\title{
Nickel-Based Superalloy Welding Practices for Industrial Gas Turbine Applications
}

\author{
M.B. Henderson ${ }^{+}$, D. Arrell ${ }^{b}$, M. Heobel ${ }^{\star}$, R. Larsson ${ }^{b}$ and G. Marchant ${ }^{c}$ \\ ${ }^{+}$ALSTOM Power Technology Centre, Whetstone, UK \\ ${ }^{\mathrm{b}}$ ALSTOM Power Sweden AB, Finspång, Sweden \\ ${ }^{c}$ ALSTOM Power (UK) Ltd., Lincoln, UK \\ *ALSTOM Power Technology Centre, Daettwil, $\mathrm{CH}$.
}

\begin{abstract}
The continued drive for increased efficiency, performance and reduced costs for industrial gas turbine engines demands extended use of high strength-high temperature capability materials, such as nickel based superalloys. To satisfy the requirements of the component design and manufacturing engineers these materials must be capable of being welded in a satisfactory manner. The present paper describes the characteristic defects found as a result of welding the more difficult, highly alloyed materials and reviews a number of welding processes used in the manufacture and repair of nickel alloy components. These include gas tungsten arc (GTA) and electron beam (EB) welding, laser powder deposition and friction welding. Many of the more dilute nickel based alloys are readily weldable using conventional GTA processes, however, high strength, precipitation hardened materials are prone to heat affected zone and strain age cracking defect formation. A number of factors are found to affect the propensity for defects: composition (aluminium and titanium content), grain size, pre and post-weld heat treatment, as well as the welding process itself (control of heat input and traverse speed). Process parameter identification is still largely empirical and a fuller understanding of the joining processes is dependent upon the development and application of more sophisticated numerical modelling techniques.
\end{abstract}

\section{$1 . \quad$ Introduction}

Nickel based superalloys are used within the industrial gas turbine (IGT) engine manufacturing industry, specifically to meet the needs of the hot gas path components. These are exposed to the most severe operating conditions where high temperature creep, tensile strength, ductility and oxidation resistance are required to withstand the loadings imposed. A range of nickel based superalloys, from dilute, solid solution strengthened alloys to the highly alloyed precipitation hardened materials, have been developed to meet the needs for high temperature structural performance and environmental resistance.

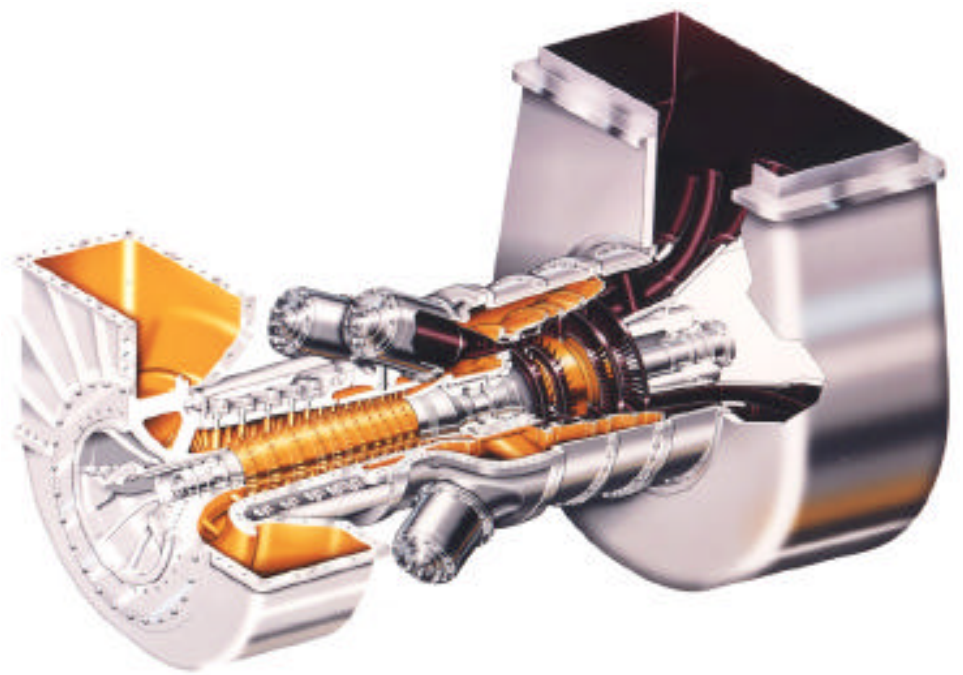

Figure 1. ALSTOM Power (UK) Cyclone gas turbine engine.

Cost effective and successful manufacture of a modern, high performance IGT engine (see Figure 1) is dependent upon the ability to join the nickel based superalloy components using methods, such as gas tungsten arc (GTA), electron beam (EB) and laser welding, and methods such as friction or inertia bonding. Weldability is defined as "the capacity of a material to be joined under the imposed fabrication conditions into a specific, suitably designed structure and to perform satisfactorily in the intended service" [1] providing fitness for purpose with minimal distortion and a controlled/limited 
numbers of defects. These procedures must be capable of being conducted in a cost-effective manner and the process parameters are largely determined using empirical methods, although more sophisticated finite element models are becoming available [2] that are capable of simulating the distortion and formation of a number of characteristic defects. The development of defects within the weld metal itself and the adjacent heat affected zone (HAZ) of the parent material is dependent upon a range of factors associated with the joint design and microstructure, form and composition of the parent alloy and any filler wire used during the welding procedure. The development of excessive distortion and residual stresses needs to be controlled by suitable assembly jigging, use of optimum heat input and traverse speed, as well as pre and post-weld heat treatment procedures, if necessary.

Increasingly to achieve through-life cost reduction targets, component refurbishment, overhaul and repair are a prime consideration for both manufacturers and operators of industrial gas turbines. Traditionally, refurbishment and repair of a number of dilute nickel alloys has been conducted using GTA welding procedures and these methods are well established within the industry. However, the high cost of near-net shape castings, such as turbine blades, vanes and casings, either for first part manufacture or part-life refurbishment, has necessitated the development and introduction of a number of more novel joining processes such as laser powder deposition and friction welding.

\section{Superalloy Welding and Characteristic Defects}

Successful first part manufacturing of a range of components, such as combustor liners (see Figure 2a), transition ducts (see Figure $2 \mathrm{~b}$ ) and exhaust exit casings, is dependent upon the ability to form fairly complex structures from wrought alloys, such as Nimonic 75, Haynes 230, IN625 and C263. Likewise, component assembly is dependent upon the ability to perform high quality-high integrity weldments, generally, for conventional solid solution strengthened alloys using conventional gas tungsten arc (GTA) welding procedures. These manufacturing methods are well established within the IGT manufacturing industry and are applied fairly routinely to solid solution and low volume fraction precipitate strengthened alloys, as mentioned above. Though routine, this technology is key to achieving the cost and reliability targets specified by the manufacturers and operators, alike. Care must be taken, however, with coarse grain size materials, which for certain applications have been heat treated to improve resistance to creep. Successful joining of coarse grained dilute materials is often restricted to power beam methods such as laser and electron beam welding that introduce lower thermal transients across adjacent to the weld bead.
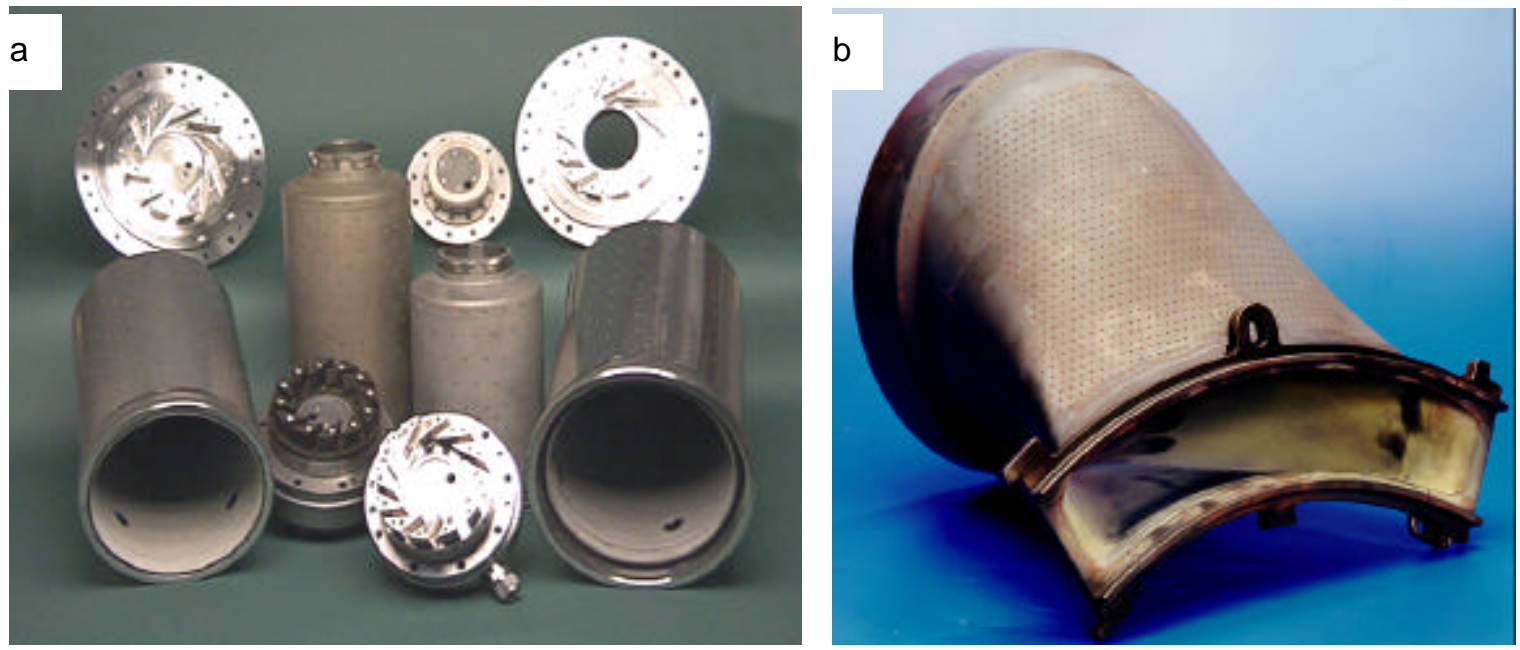

Figure 2. a) ALSTOM Power G30 range of lean burn DLE industrial gas turbine combustors.

b) ALSTOM Power industrial gas turbine Combustor transition duct.

Increasingly, there is a requirement to conduct high integrity, defect-free (or limited) welding of higher temperature capability, precipitation strengthened alloys such as IN718, Waspaloy, IN939, IN738 etc, as well as more advanced alloys such as those used for directionally solidified and single crystal castings, such as MarM247 and CMSX-4. These are used for the manufacture of a wide range of hot gas path components such as discs, casings, stator vane segments and turbine blades. Welding of these alloys presents much more of a problem due to their highly alloyed nature and the more complex precipitation strengthening mechanisms needed to provide high temperature strength in 
service. The inherent capabilities of these alloys (ie., the strengthening mechanisms) often interact in a detrimental manner with the thermal and mechanical loadings generated by the heat source, component mass and jigging constraints applied during the welding procedure. Local changes in microstructure adjacent to the weld bead, such as particle coarsening and dissolution and grain growth within the HAZ can lead to significant property changes during the heating cycle, which interact with the "thermal fight" arising from precipitation within the alloy during cooling. In an effort to minimise these interactions many higher strength alloys are welded in the solution annealed or softened condition. However, despite these efforts the more highly strengthened alloys continue to be susceptible to three main types of cracking and defects. These are summarised as follows:

\section{- Solidification cracking}

Solidification cracking, such as shown in Figure 3a, occurs within the newly formed weld bead when the mushy, two-phase liquid-solid region experiences tensile stresses and the high fraction of solid present (typically fs $>0.9$ ) restricts the flow of liquid metal to backfill the interdendritic regions. These are torn apart by tensile thermal stresses generated behind the weld bead as it progresses. Solidification crack formation is dependent upon a number of contributory factors such as thermally induced stresses and strains being generated behind the weld bead, that coincide with a high fraction of solid being present in the mushy zone, solidification and microsegregation, viscous flow of liquid metal and crack initiation and propagation effects. Formation is promoted by a wide solidification range for the alloy (i.e., dilute and eutectic forming alloys are less susceptible) and low welding traverse speeds that promote the generation of tensile stresses adjacent to the weld due to contraction of the surrounding solid material. This form of welding defect in nickel based alloys can, generally, be avoided by optimising the welding procedures used. A fuller discussion of the factors leading to solidification cracking and the analytical and finite element modelling methods used to simulate these phenomena has been given elsewhere [3].

Another common type of defect found during welding of thin plate superalloy components, that is often associated with solidification cracking, is a continuous grain boundary that forms along the centreline of the weld bead at intermediate to high heat input levels and high traverse speeds (see Figure $3 \mathrm{~b}$ ). A fuller description of the formation of centreline grain boundary and the dendrite-tip growth kinetics model capable of predicting its formation have been given elsewhere [4]. Formation of this defect is promoted by higher alloying additions and impurity levels and is characterised by a sharp teardropshaped weld pool, a coarse columnar grain structure across the weld bead and a high volume fraction of eutectic and brittle phases along the centreline. This segregation may lead to incipient melting during subsequent heat treatment and localised corrosion of the weld bead during service exposure.

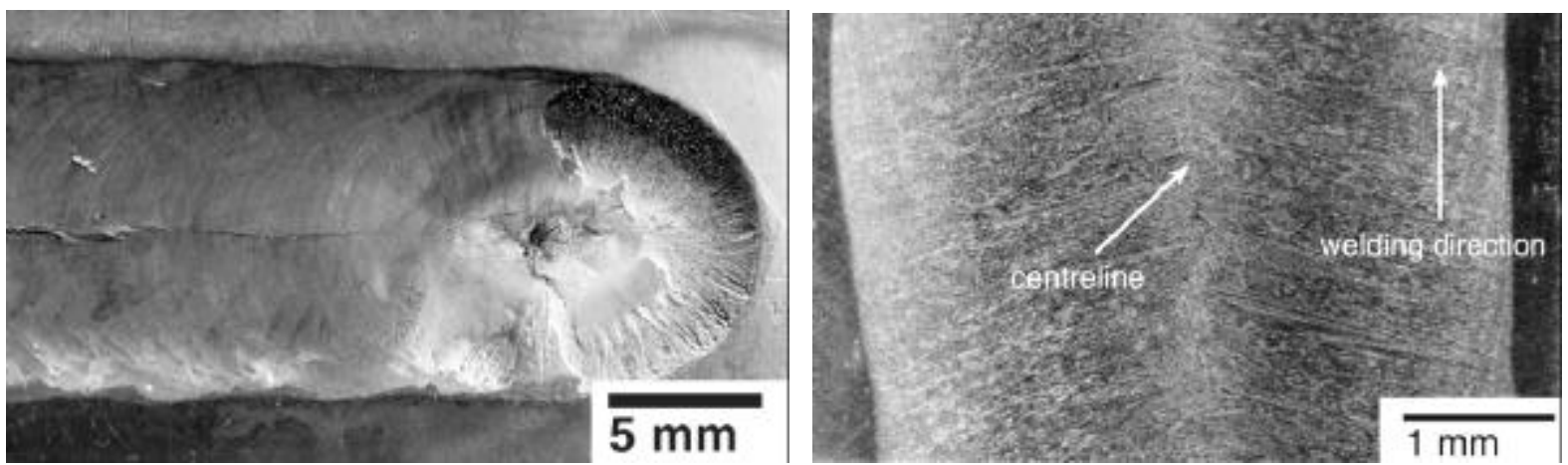

Figure 3. a) Solidification cracking following autogenous GTA welding of IN718 sheet. [5]

b) Centreline grain boundary formation in IN718 sheet.

\section{- Grain boundary liquation cracking}

Grain boundary liquation cracking or heat affected zone (HAZ) fissuring, as shown in Figure 4 for GTA welding of IN718, occurs within the HAZ adjacent to the weld bead as a consequence of local dissolution of grain boundary phases, such as primary $M C$ and $M_{6} C$ carbides, Laves phases and $\sigma$ phase $[6,7,8,9]$. Under rapid heating, the grain boundary phases are unable to dissolve fully into the surrounding matrix and partial dissolution leads to the formation of a low melting point eutectic and melting of the grain boundary region. A liquid film forms on grain boundaries within the HAZ, often away from the fusion zone in regions where grain coarsening has occurred, which fails under the tensile thermal stresses generated immediately behind the weld bead. 
Grain boundary liquation has been found to be the primary cause of HAZ hot cracking in alloys such as IN718 [9] and is associated with grain boundaries rich in those elements that form primary MC-type carbides (NbC and TiC in IN718, for example). Susceptibility to HAZ fissuring is dependent upon alloy composition (carbon, boron etc), grain size and grain boundary character [6], and for coarse grain size materials (> ASTM 6), the weld traverse speed. Increasing traverse speed increases the HAZ cracking susceptibility as this influences the thermal gradients and stress state within the HAZ. Generally, fine grained wrought materials, such as wrought IN718, are less susceptible and are considered to be readily weldable provided suitable pre and post-weld heat treatments are applied; typically the material is welded in the solution annealed condition. An increased grain size decreases the grain boundary area per unit volume and increases the amount of segregation on the grain boundaries. In addition, it is clear that the segregation of tramp and impurity elements such as boron, sulphur and phosphorus also plays a role $[10,11]$ and is promoted by coarser microstructures. These elements act to suppress the eutectic melting temperature and consequently increase the HAZ fissuring susceptibility, however, it appears to be possible to control their segregation behaviour with suitable solution heat treatment procedures $[6,7]$.
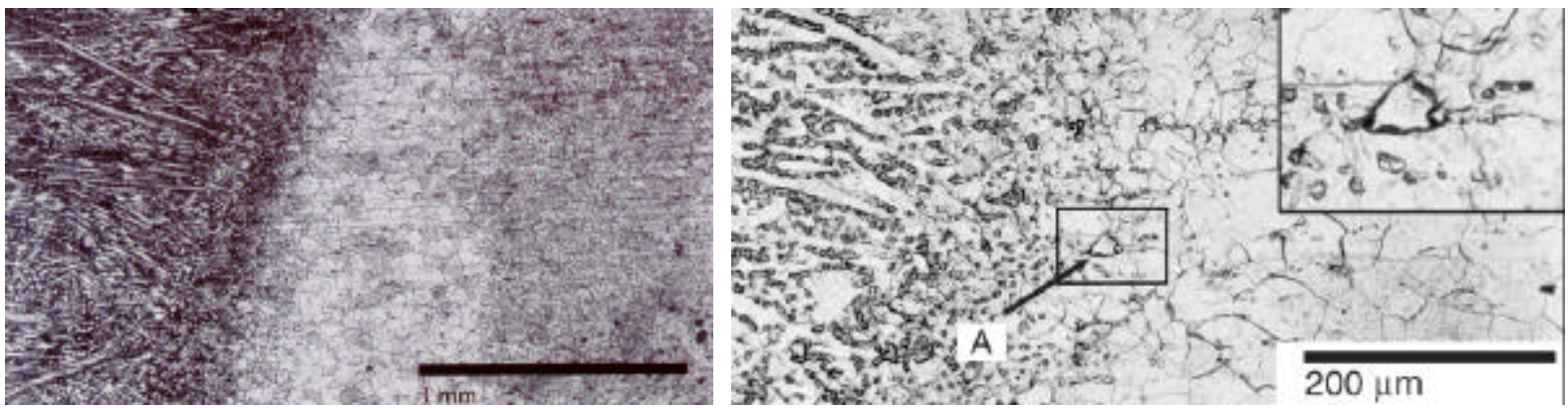

Figure 4. Grain coarsening and HAZ liquation cracking at A following autogenous GTA welding of IN718 sheet. [5]

Attempts have been made to improve the HAZ cracking resistance of high temperature casting alloys, such as IN939, by reducing the impurity levels present in the alloys and refining the final microstructure [12]. However, the coarse grain size microstructures that are typically found for investment cast or near net shaped cast parts are generally found to be susceptible to HAZ cracking. It is evident that for a number of fine grained, precipitation strengthened alloys, such as IN718 and Waspaloy, it is possible to produce high quality welds without HAZ cracking problems by controlling the alloy composition, grain size, weld traverse speed and heat input by using EB welding methods. However for a wide range of materials, in particular the high strength cast alloys such as IN738, IN939, MarM247 and cast forms of IN718, it has, generally, not been possible within a production environment to avoid HAZ fissuring using conventional GTA and EB welding methods.

\section{- Strain age cracking}

Strain age or re-heat cracking, generally, occurs in $\gamma^{\prime}-\mathrm{Ni}_{3}(\mathrm{Al}, \mathrm{Ti})$ precipitate strengthened alloys during post-weld heat treatment or subsequent high temperature service due to the presence of either residual stresses developed during manufacture, or applied stresses arising from service exposure. These defects are characterised by intergranular micro-cracking in either the HAZ or weld bead and form as a consequence of precipitation and hardening of the alloy during thermal exposure and transfer of solidification strains onto the grain boundaries [10,13], often with carbides acting as crack initiation sites. It is common practice to attempt to relieve residual stresses arising from the welding procedure by means of post weld heat treatment. However, often the stress relieving temperature is greater than the ageing temperature of the alloy and this leads to a transient precipitation period during post weld heating that hardens the alloy and leads to excessive strain localisation on grain boundaries within the HAZ and weld bead during heating. Conventionally, the most effective means of limiting the extent of strain age cracking is to overage the material prior to welding. This can be combined with the use a more ductile, dilute alloy filler wire (for example, IN625 or C263) and by careful control of the heating and cooling cycles during post-weld heat treatment [10]. However, welding of more difficult alloys in the fully solutioned or over aged condition can lead to HAZ cracking due to re-precipitation of strengthening phases during cooling immediately after welding and thus lead to cracking sensitisation. 


\section{Weldability Assessment Diagrams}

The susceptibility to strain age cracking is promoted by high additions of both $\mathrm{Ti}$ and $\mathrm{Al}$, as these promote $\gamma$ precipitation, and elements such as carbon, sulphur and boron. Alloys such as IN718 are considered as being less susceptible due to the more sluggish precipitation reaction of $\gamma^{\prime \prime}-\mathrm{Ni}_{3}(\mathrm{Nb}, \mathrm{Ti}$, $\mathrm{Al}, \mathrm{Mo}$ ) precipitates. The weldability of nickel based superalloys and the susceptibility to strain age cracking is often assessed, qualitatively, by plotting the Al vs. Ti content of the alloy, as shown in Figure 5. When the total Al+Ti level for a particular alloy exceeds a critical value (often taken as 4wt\%) it is deemed to be difficult to weld and increasingly unweldable with increasing $\mathrm{Al}+\mathrm{Ti}$ content. This over simplification of the factors contributing towards weld cracking does not take any account of variation in microstructure due to different thermomechanical processing and heat treatment procedures. Those alloys that lie either side of the critical $4 \mathrm{wt} \%$ limit need to be treated carefully in terms of the heat treatment, grain size and cooling rates used.

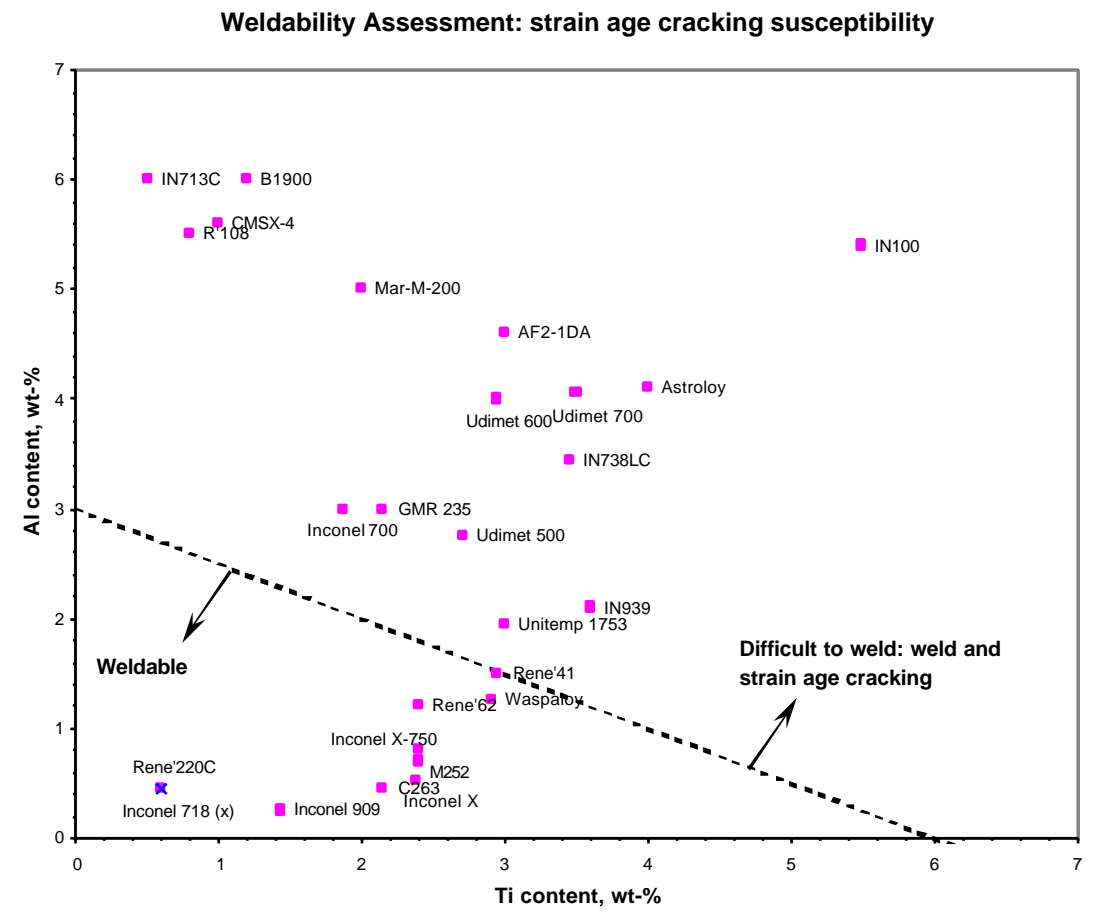

Figure 5. Weldability assessment diagram for a range of nickel based superalloys (after[10]).

Recent weld research programmes have been aimed at establishing a more systematic approach to evaluating and predicting the weldability of nickel based superalloys in terms of the process parameters (i.e., heat/power input and traverse speed) applied during the welding procedure for a particular alloy, welding process and joint configuration. Figure 6 shows a typical Weldability Process Diagram for wrought sheet IN718, which illustrates the defect formation regimes as discussed above, which have been identified by a combination of analytical and numerical modelling techniques in conjunction with well characterised experimental validation of the weld defect formation zones. The limits of these boundaries identify a central region of weldability for this alloy. With the advent of more sophisticated, non-linear finite element modelling and data analysis tools it should be possible to identify similar weldability diagrams for a range of alloys that are currently considered to be difficult to weld and provide a more comprehensive tool to define weldability limits for nickel based superalloys.

\section{Nickel Based Superalloy Component Welding Practices}

\subsection{Conventional Welding and Repair Procedures Using GTA}

As discussed previously, conventional, manual and automatic GTA welding procedures are used in the production of complex shaped components, such as the transition duct shown in Figure 7 . This unit is manufactured in the solid solution and carbide precipitate strengthened alloy Haynes 230 sheet and forged plate. GTA methods are applied routinely, with little difficulty concerning the integrity of the joint (see Figure 8a). The main issues for this component are associated with the high cost of 
manufacture of the end-pieces (letterbox and combustor attachment ring) and the dependence on manual, skilled sheet metal working and welding procedures.

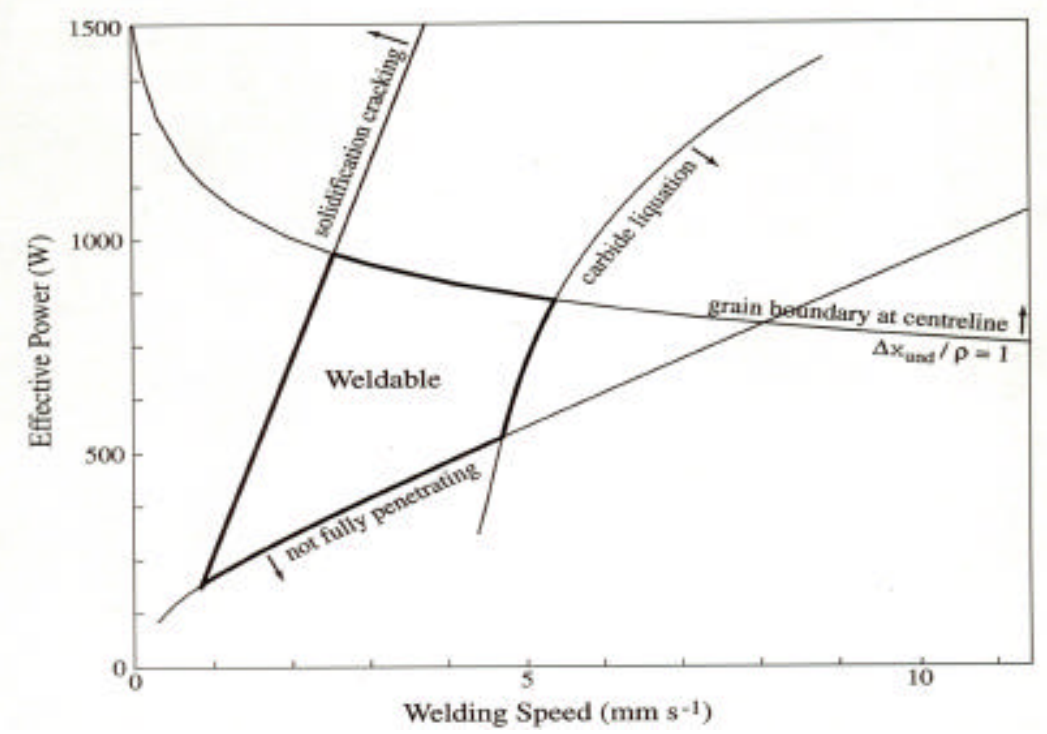

Figure 6. GTA Weldabilty Process Diagram for IN718 plate (after [5]).

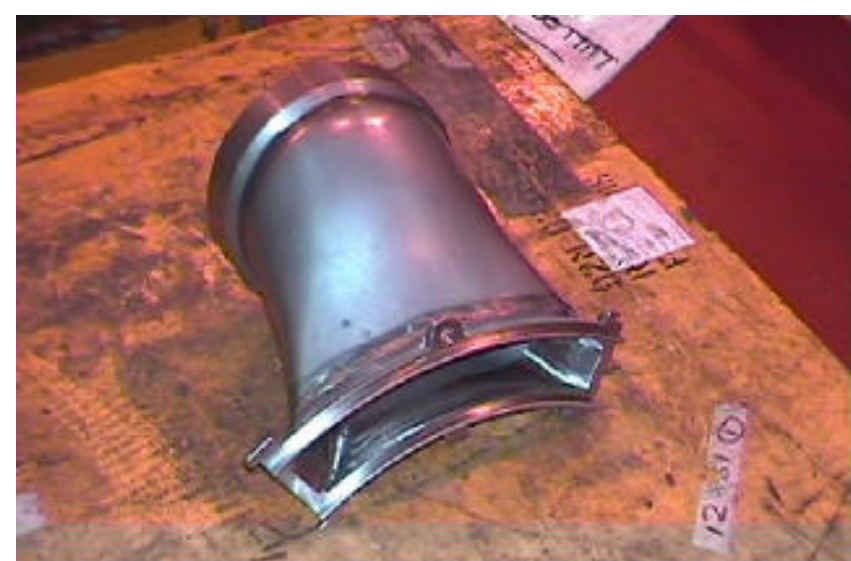

Figure 7. ALSTOM Power UK Haynes 230 transition duct.

In an effort to reduce the component costs, a manufacturing and weldability study has been conducted to assess the potential for using cast $\mathrm{H} 230$ for the letterbox and attachment ring. A low boron cast alloy variant of $\mathrm{H} 230$ was used to manufacture a number of rings and letterbox pieces that were then GTA welded to sheet $\mathrm{H} 230$. These trials (see Figure $8 \mathrm{~b}$ ) found good weldability and integrity of the joint, however, other manufacturing issues prevented the use of cast $\mathrm{H} 230$ and further work is currently investigating the use of other alloys.
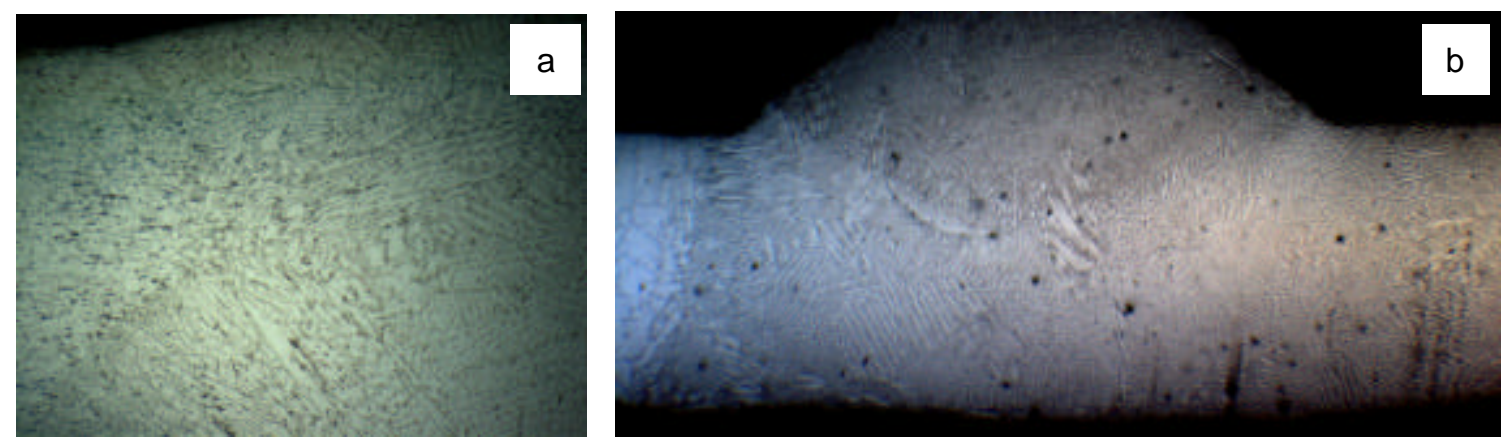

Figure 8. Examples taken from GTA welding trials in Haynes 230:

a) Section through wrought $\mathrm{H} 230$ sheet GTA weld bead.

b) Section through wrought $\mathrm{H} 230$ sheet to cast $\mathrm{H} 230$ attachment ring. 
To achieve reductions in the costs of manufacture and operation, a key requirement is the ability to conduct cost effective repairs of newly manufactured components and service exposed parts. One example, shown in Figure 9, is the refurbishment of investment cast IN939 stator segment rings. These parts are, relatively, expensive to replace if damaged during service and production casting yields can be quite low if localised repairs of certain sections of the component are not possible. To this end a series of welding trials have been conducted using GTA welding of both IN738 and IN939, incorporating more ductile alloy filler wires, such as C263 and IN625. Welding is conducted with the components in the fully solutioned condition, which is followed by a post-weld standard solution anneal and ageing treatment. Example sections through these repair trials are shown in Figure 10. As shown, microcracking of the HAZ has been found and proves difficult to avoid. The cracking often propagates into the weld bead but the overall length is limited to about $0.5 \mathrm{~mm}$, which is deemed to be acceptable for these components. It is common practice, and some would say critical, to place limitations on the extent of localised repair work that can be conducted. For example, the total length of allowable weld repair to the vane trailing edges is of the order of $20 \mathrm{~mm}$, but tighter limits are required for other regions of the stator ring.

These localised GTA weld repair procedures are also used to carry out rotor blade tip build up to recover damaged parts and loss of clearances that impact upon gas sealing and efficiency.
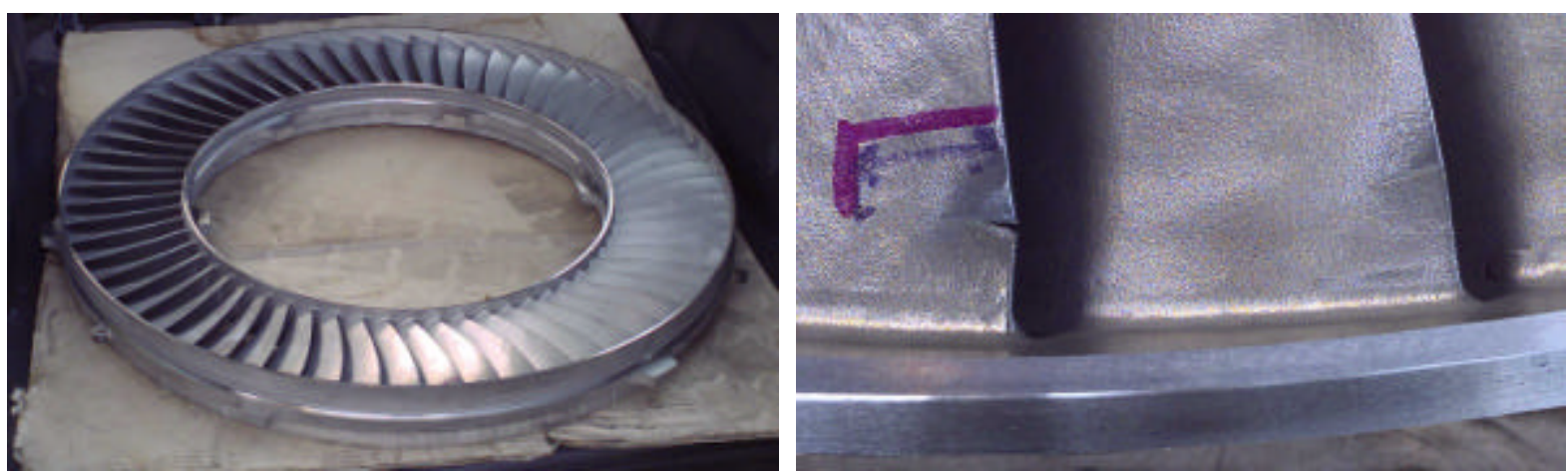

Figure 9. Investment cast IN939 stator segment ring showing damaged/defective vane trailing edge.

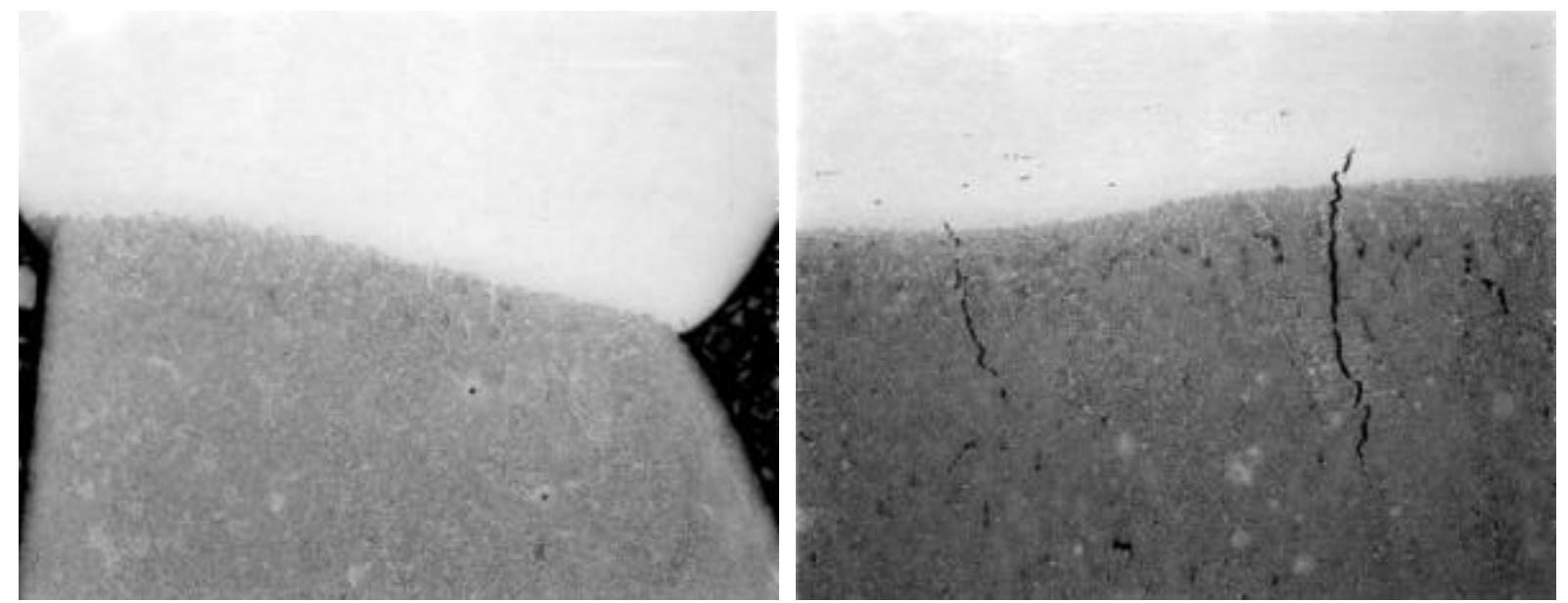

Figure 10. Localised GTA weld repair of IN939 vane trailing edge using IN625 filler wire. HAZ microfissuring is limited to approximately $0.5 \mathrm{~mm}$.

\subsection{Electron Beam Welding of GT10B/C and GTX100 Compressor Rotors}

ALSTOM Power Sweden AB makes extensive use of EB welding techniques to manufacture the compressor rotors for the majority of their gas and steam turbine engines. This process involves the welding of separate disc forgings manufactured in either $12 \% \mathrm{Cr}$ or austenitic stainless steels and nickel-based superalloys, such as IN718 and Nimonic 901. EB-welding of steel discs to nickel based superalloy discs (initially Nim901 and more latterly IN718) has been conducted since 1990. The process uses a $150 \mathrm{kV}$ EB welding facility, capable of providing a maximum heat input of 300 
$\mathrm{kW} / \mathrm{mm}^{2}$, which is far higher than that achievable using conventional electric arc welding methods, typically providing no more than $10 \mathrm{~kW} / \mathrm{mm}^{2}$. The high intensity parallel beam of electrons allows the production of much deeper and narrower weld melts, as shown in Figure 11. In addition to providing high quality-high integrity welded joints for a range of steel and nickel disc materials, this process enables the production of high quality welds of dissimilar materials, as illustrated by the joining of IN718 superalloy discs to austenitic steel discs, as shown in Figure 12.

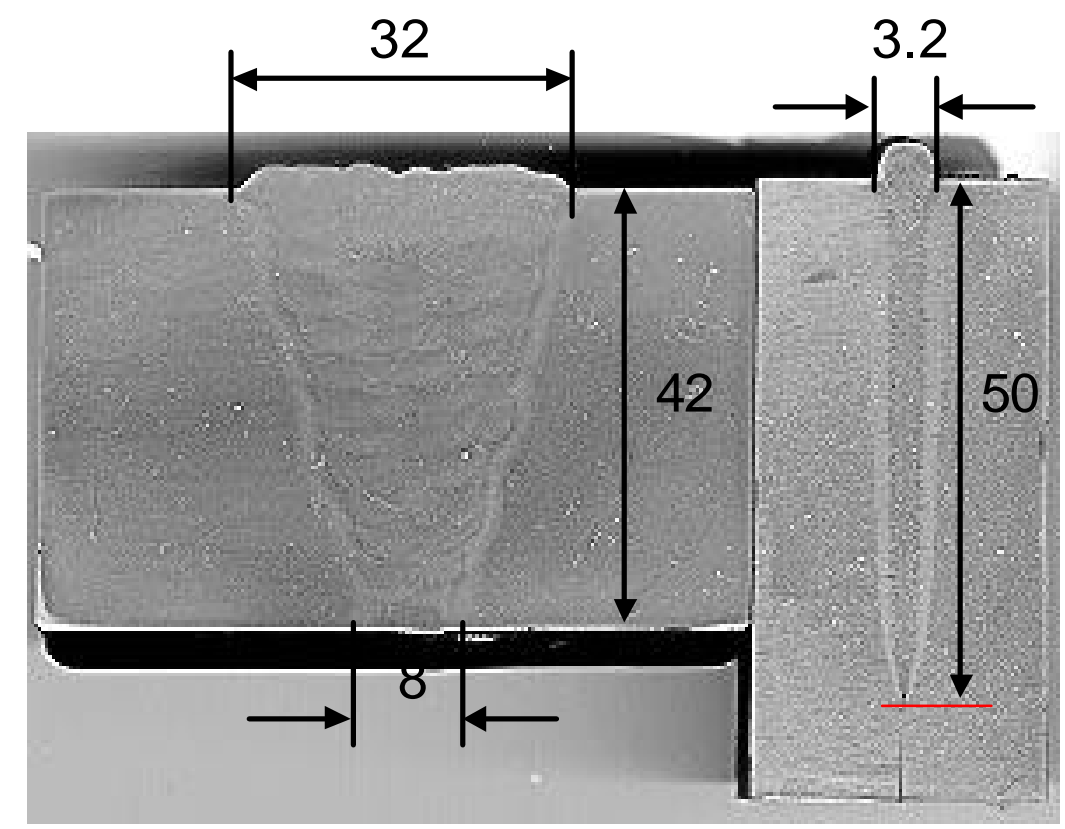

Figure 11. Comparison of a conventional GTA multipass weld (left) with a single pass EB weld of similar depth.

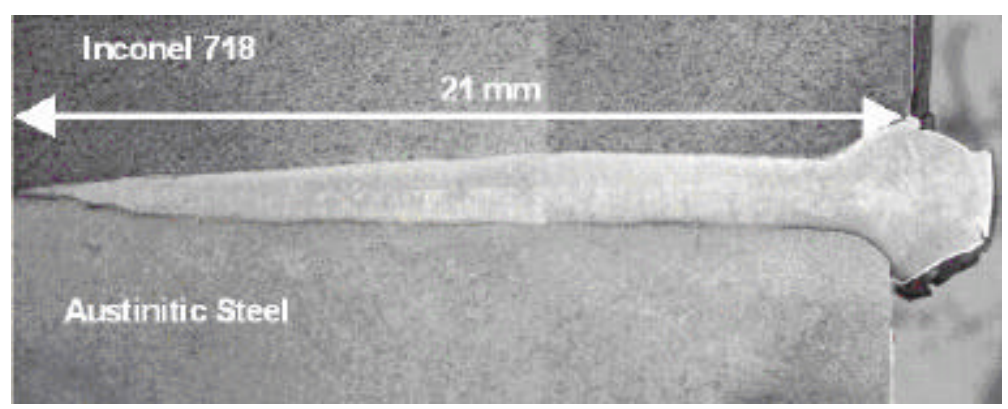

Figure 12. Example of an EB welded IN718 compressor disc (top) joined to an austenitic stainless steel disc.

In the case of the 25 MW GT10B and 29 MW GT10C gas turbine engines, both of which are twin shaft designs intended for both electrical and mechanical drive applications, the rotors are formed from a sequence of EB-welded steel and nickel-based alloy discs. The GT10B has a 10-stage compressor rotor as shown in Figure 13, in which the final four high-pressure stages to the right hand side are made from IN718 discs and the lower pressure stages are made from Swedish Standard 2596 austenitic stainless steel. All the discs are fully machined prior to welding and full alignment of the whole rotor (without further machining) is carried out to a maximum tolerance for both length and eccentricity of $+/-0.06 \mathrm{~mm}$. In practice this is typically in the range of 0.03 to $0.04 \mathrm{~mm}$, including disc pack manufacturing tolerances, which are typically half of the total error. The largest disc assembly welded in a single operation by ALSTOM Power Sweden is the compressor disc pack for the $44 \mathrm{MW}$ GTX100A gas turbine engine, which is a fully steel construction and is shown in Figure 14. 


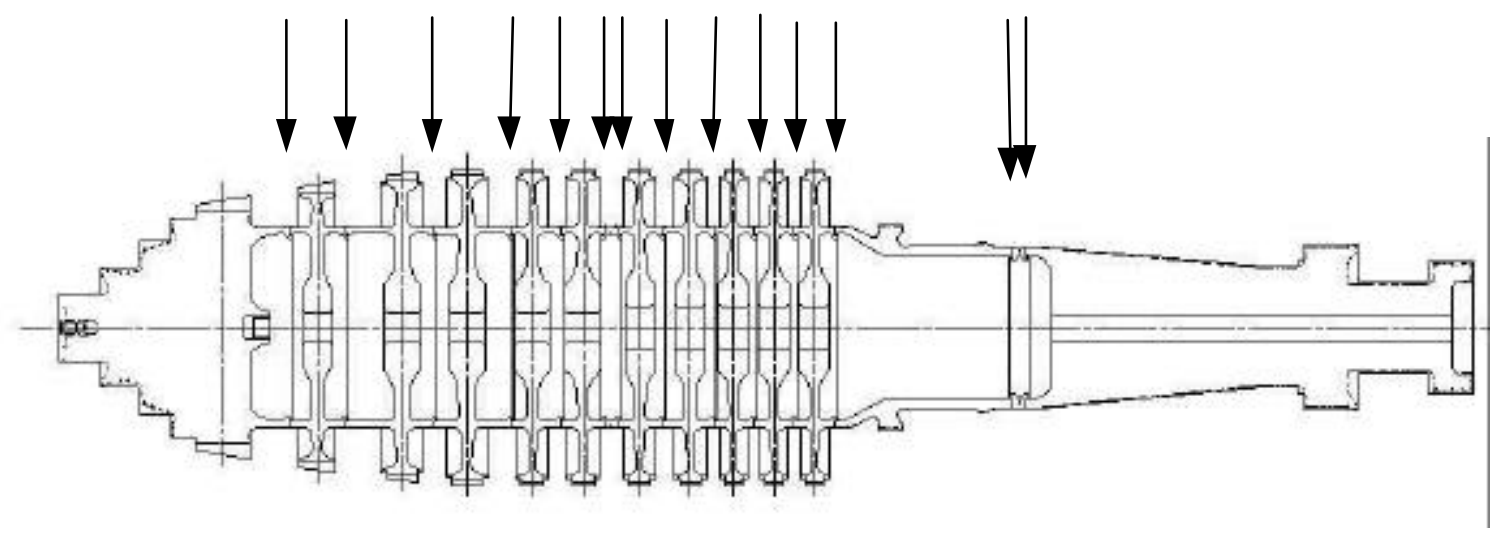

Figure 13. General arrangement for ALSTOM Power GT10B fully welded compressor rotor. A series of EB welds, as indicated by arrows are used to construct the rotor. The four high pressure discs to the right hand side are made of IN718 forgings and are EB welded to the austenitic stainless steel rotors.

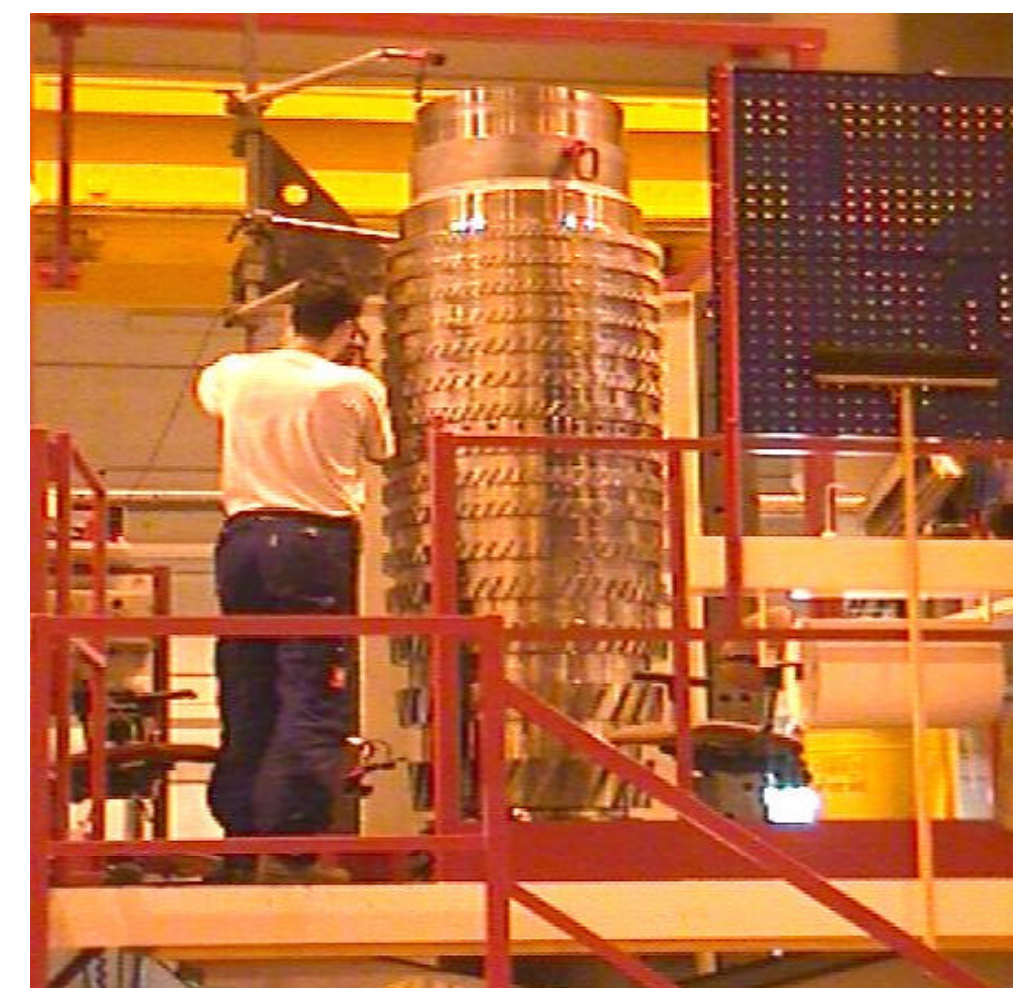

Figure 14. ALSTOM Power GTX100 EB-welded compressor rotor assembly.

The welds produced by the EB welding process have proved to be extremely reliable. The GT10B units, which are currently in service, have amassed up to 2.2 million operating hours without a single reported weld-induced failure in the compressor rotor.

\subsection{Laser Tip Welding of Single Crystal Materials}

Cost effective overhaul of large industrial gas turbine advanced blading systems using, for example, single crystal blades/vanes requires the introduction of new repair procedures such as the Laser Metal Forming (LMF) Technology. Laser metal forming is a process, whereby powder or wire material is deposited onto a substrate by local melting using a high power laser beam. In this way new material can be added onto an existing bulk body which makes the process attractive for local repair of damaged, expensive parts such as gas turbine blades. LMF processes for gas turbine applications are currently under development at the ALSTOM Power Technology Centre, Daettwil. 
The LMF process allows the build up of blade tips with minimum heat impact to the component, such that during the laser repair procedure cracking and recrystallisation can be avoided and the single crystal orientation of the substrate is maintained through the interface into the deposited material. Single crystal blade tips have been rebuilt using a new generation of fibre coupled high power diode lasers (ROFIN DF012HQ) and robot manipulation of the laser/powder head (see Figure 15). The powder and laser beam are combined in a coaxial laser powder head that also integrates an on-line process monitoring device.

High power diode lasers have only recently become available with adequate beam quality for laser metal forming. With today's performance they have become a very attractive energy source for the LMF process due to their small footprint, high efficiency and ruggedness. More than $1000 \mathrm{~W}$ of continuous wave (CW) laser power can be easily transmitted to a six axes robot (ABB IRB4400) through flexible optical fibres, which results in $3 \mathrm{D}$ cladding capability at reasonable investment costs.

Optimum processing conditions were derived from systematic studies of process parameter influence on the microstructure of the deposited layers. Matched epitaxial growth can be obtained on single crystal substrates if suitable process parameters are chosen. As a simple guideline the ratio between the thermal gradients in the weld zone and the solidification velocity should be higher than a material dependent threshold value, if single crystal growth is desired. The use of fibre-coupled diode lasers results in a top-hat laser intensity distribution, which helps to meet this criterion.
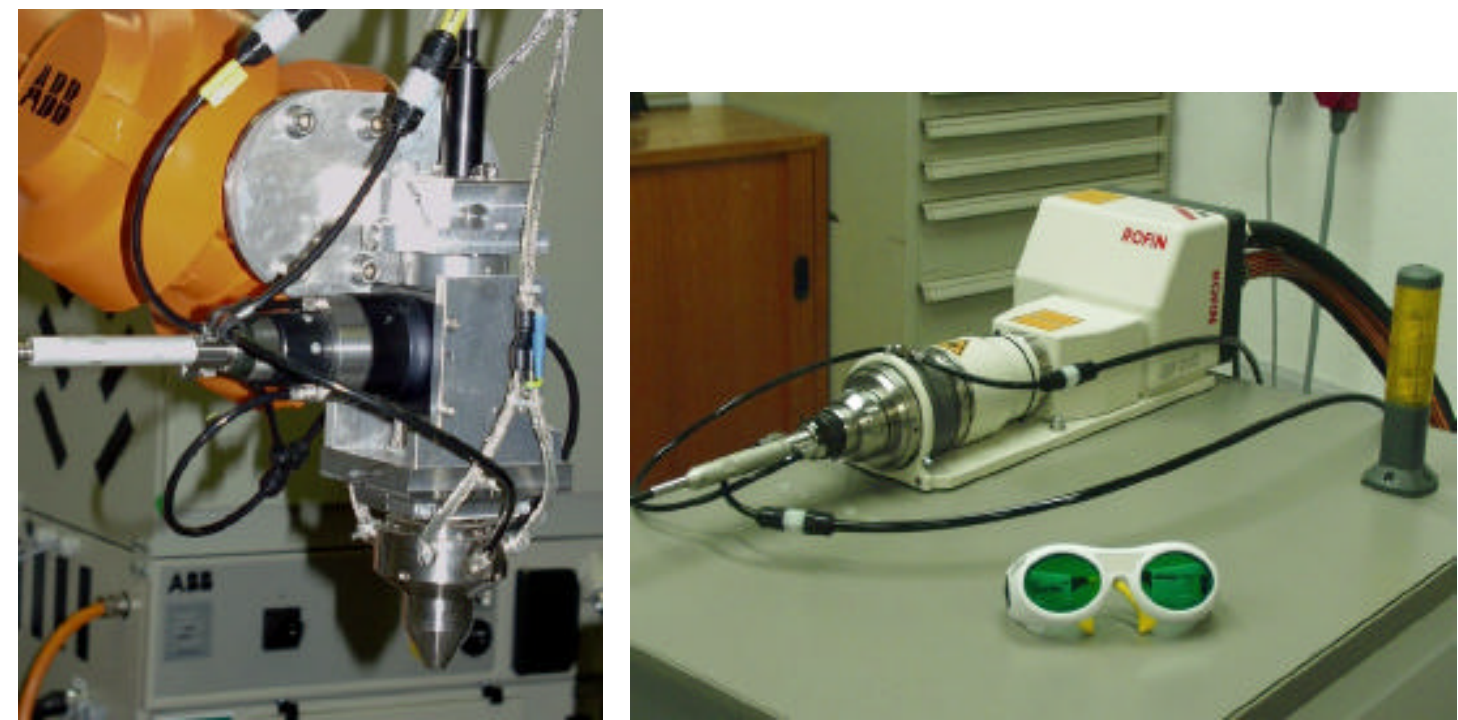

Figure 15. Equipment used for laser metal forming at the ALSTOM Power Technology Centre: A fibre coupled high power diode laser (left) delivers more than $1000 \mathrm{~W}$ of laser power to a coaxial powder nozzle (right) which is manipulated by a 6 -axis robot.

Figure 16 shows epitaxial laser metal forming (E-LMF) of a GT26 high pressure turbine blade tip. Powder is supplied through a commercially available Sulzer Metco Twin 10C powder feeder using Argon as a protection gas. Usually, 5 to 8 layers of new material are added on top of each other in order to rebuild a blade tip of 2-3 $\mathrm{mm}$ in height. The accuracy of the robot is sufficient to allow near net shaped cladding. In most cases post-weld machining is reduced to a simple grinding to length operation.

Figure 17 shows a crosscut through a section of the blade tip. Fully epitaxial growth through several layers is evident. The epitaxial material build-up results in matched thermo-physical properties between substrate and deposit and therefore in a longer blade lifetime. Due to the high cooling rate the dendritic structure of the deposit is much finer than that of the substrate and this results in a more homogeneous distribution of the coating elements. It can be also seen from Figure 17, that crack-free material build up can be achieved on the single crystal turbine blade, but this is dependent upon careful choice (and control) of the process parameters and a suitable substrate-filler material combination. Under optimum conditions the single crystal microstructure of the deposit can be extended to the edges of the blade where polycrystalline material of the plasma sprayed MCrAlY 
overlay coating may be present. Usually the top of the last layer solidifies with polycrystalline microstructure. This thin surface layer can be either transformed into single crystal material by a final remelting step (without powder supply) or simply be machined away.

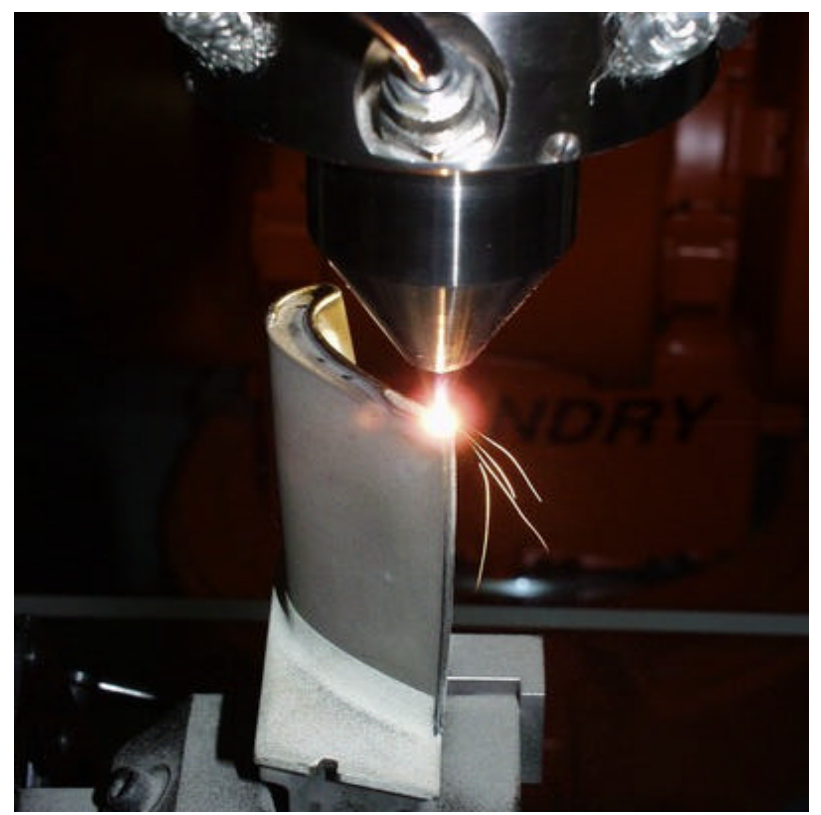

Figure 16. Epitaxial laser metal forming (E-LMF) on an ALSTOM Power GT26 single crystal turbine blade tip.

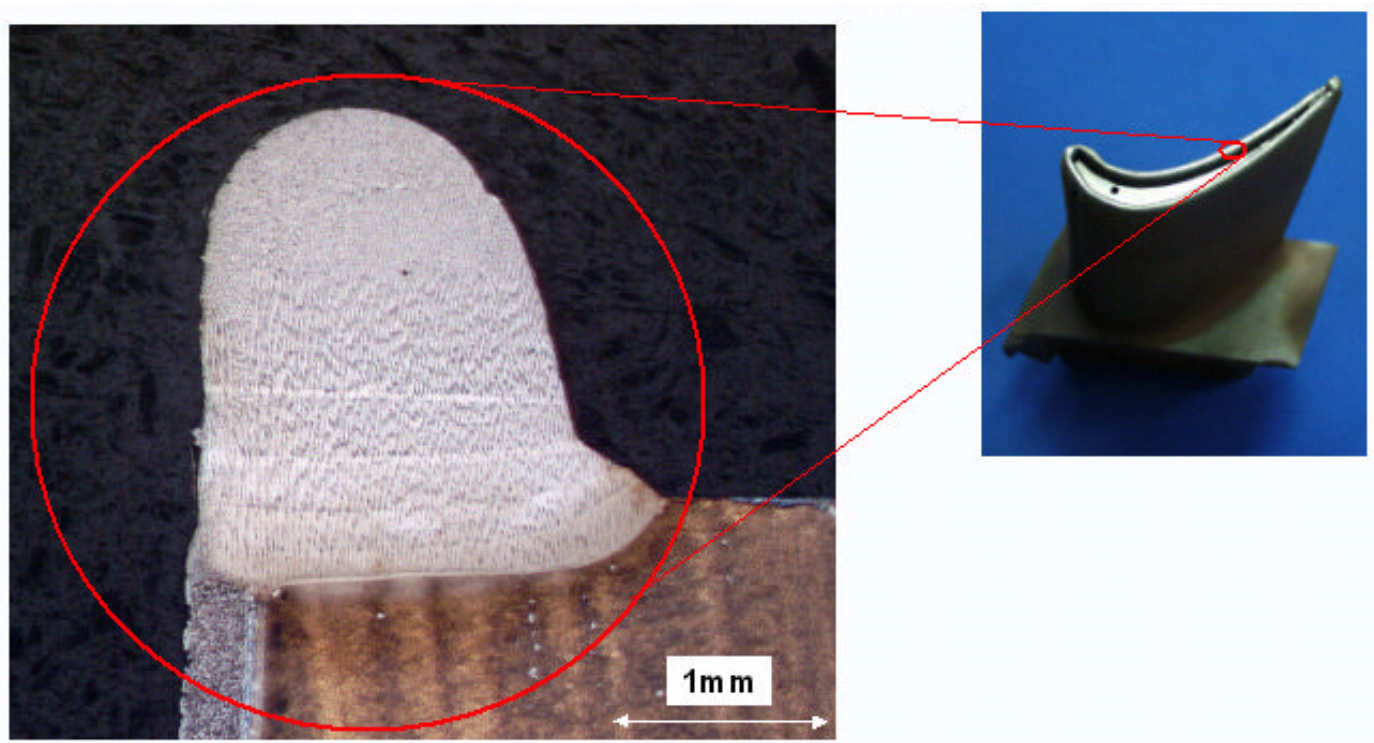

Figure 17. Microstructure of a laser metal formed single crystal, turbine blade tip. Five layers of ALSTOM's proprietary weld filler have been deposited on top of each other. The picture to the right shows the turbine blade directly after welding prior to post-weld machining.

It can be seen from Figure 17 that the remelt and heat affected zone is limited to a shallow surface layer which is approximately $500 \mu \mathrm{m}$ deep. The material underneath is not affected and maintains its character after the welding operation has been completed.

\subsection{Feasibility Studies for Friction Welding Repair of IN939 Stator Ring}

In an effort to improve the integrity of the repair welded sections of investment cast IN939 stator rings, a series of friction welding trials have been conducted by TWI on behalf of ALSTOM Power. These trials were aimed at evaluating the feasibility of this process for conducting localised repairs of difficult to weld materials, such as IN939 and IN738. Both friction surfacing and the Hopkinson 1-shot 
technique of friction welding have been evaluated on $125 \times 25 \times 3 \mathrm{~mm}$ flat plates of IN939 using suitably sized consumable IN939 bars.

Following initial assessment and development of the V-preparation profile, welding was conducted using a Herbert milling machine capable of producing $250 \mathrm{kN}$ of down force at rotational speeds of up to $1400 \mathrm{rpm}$, and has a maximum power rating of $22 \mathrm{~kW}$. Fixtures and fittings were designed and manufactured by TWI and an inert gas shielding system was produced. Typical examples of metallographic sections are shown in Figures 18 and 19 for friction surfacing and the Hopkinson 1shot technique, respectively. These initial trials demonstrated that the friction processing of IN939 was feasible and that both processes appear capable of providing good metallurgical bonding using acceptable levels of down force, making the proposed application (blade repair on a large cast component) viable.

\subsection{Friction Stir Welding of Oxide Dispersion Strengthened (ODS) Alloys}

In an effort to facilitate higher temperature capability combustion systems, a technology development programme has, within COST 522, targeted the development of sheet forming methods for the production of ODS combustor liners and transition ducts. These materials are notoriously difficult to join using conventional methods such as welding or brazing and it has been proposed that friction stir welding may prove to be a viable solution. These trials are currently underway and preliminary results look promising, as shown in Figure 20.

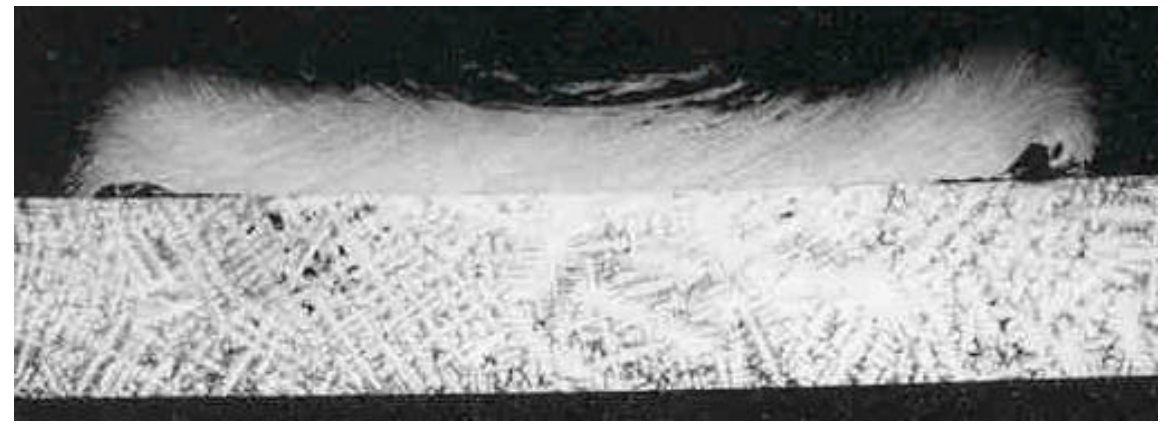

Figure 18. IN939 friction surfacing welded section [14].

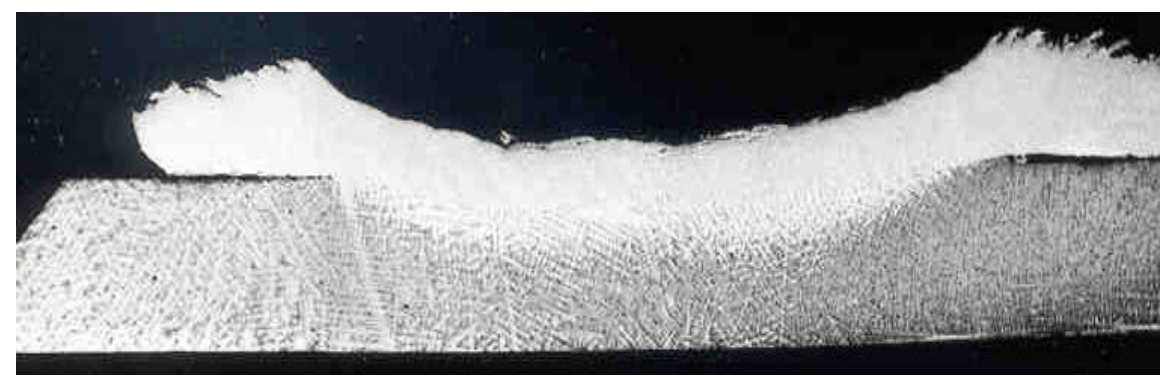

Figure 19. IN939 Hopkinson 1-shot technique friction welded section [14].

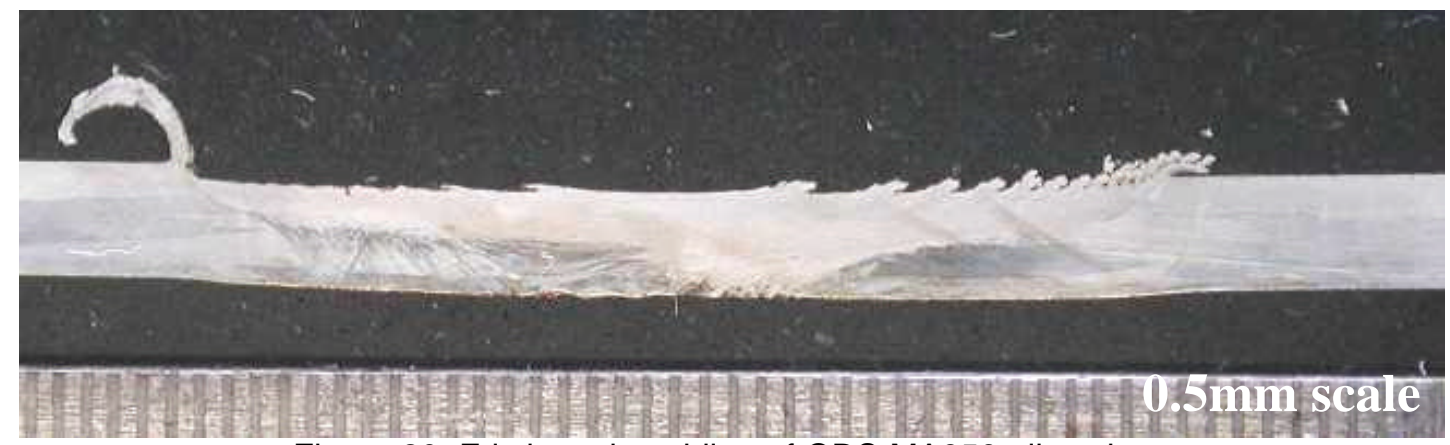

Figure 20. Friction stir welding of ODS MA956 alloy sheet. 
a) Cost effective manufacture of modern, high performance IGT engines is dependent upon the ability to join a range of nickel based superalloys using gas tungsten arc, electron beam and laser welding and, increasingly, methods such as friction or inertia bonding.

b) Many of the more dilute nickel based alloys are routinely welded using conventional GTA processes and this technology is key to achieving the cost and reliability targets specified by the manufacturers and operators.

c) Welding of high strength, precipitation hardened materials presents much more of a problem as these are prone to heat affected zone and strain age cracking that limits the manufacturing and repair weldability for these alloys. Consequently, more novel joining methods such as laser powder deposition and friction welding are being evaluated.

d) A number of factors are found to affect the propensity for defects: composition (aluminium and titanium content), grain size, pre and post-weld heat treatment, as well as the welding process itself (control of heat input and traverse speed).

e) Electron beam welding and laser powder deposition methods are being used increasingly to produce high integrity-high performance weldments in a range of gas turbine components, such as nickel based rotor discs and turbine blades.

f) Process parameter identification is largely empirical and a fuller understanding of the joining processes is dependent upon the development and application of more sophisticated numerical modelling techniques.

\section{Acknowledgements}

The authors gratefully acknowledge ALSTOM Power for permission to publish this article, as well as colleagues from the materials and turbine design groups. Many thanks are due to Prof. Roger Reed of University of British Columbia and Chris Bagley, M.J. Russell and P.L. Threadgill of TWI for helpful discussion and provision of a number of micrographs, as indicated.

\section{References}

1. Standard Welding Terms and Conditions, ANSI/AWS A3.0-89, American Welding Society, 1989.

2. R.C. Reed, H.J. Stone, D. Dye, S.M. Roberts and S.G. McKenzie, "Process Modelling of the Electron beam Welding of Aeroengine Components." Proc. Conf. On Superalloys 2000, T.M. Pollock et al., Eds. Seven Springs, Champignon, USA (2000), p. 665.

3. O. Hunziker, D. Dye, S.M. Roberts and R.C. Reed, "A Coupled Approach for the Prediction of Solidification Cracking During the Welding of Superalloys." Proc. Conf on Numerical Analysis of Weldability, Graz-Seggau, Austria (1999).

4. O. Hunziker and R.C. Reed, Acta mater., 48, (2000), pp.4191-4201.

5. D. Dye, O. Hunziker, S.M. Roberts and R.C. Reed, "Modelling of the Mechanical Effects Induced by the Tungsten Inert Gas Welding of IN718 Superalloy." Met. Trans., 32A, (2001), pp. 17131725.

6. H. Guo, M.C. Chaturvedi, N.L. Richards and G.S. McMahon, "Interdependence of Character of Grain Boundaries, Intergranular Segregation of Boron and Grain Boundary Liquation in Simulated Weld Heat Affected Zone in IN718." Scripta mater., 40, No. 3, (1999), pp. 383-388.

7. X. Huang, M.C. Chaturvedi and N.L. Richards, "Effect of Homogenisation heat treatment on the Microstructure and Heat Affected Zone Microfissuring in Welded Cast Alloy IN718." Met., Trans., A, 27A, (1996), pp.785-790.

8. L. Nastac and D.M. Stefanescu, "Computational Modelling of NbC/Laves Formation in IN718 Castings.” Met. Trans., A, 28A, (1997), pp.1582-1587.

9. Y.M. Yaman and M.C. Kushan, "Hot Cracking Susceptibilities in the Heat Affected Zone of Electron Beam Welded IN718." J. Mat., Sci., Letters, 17, (1998), pp.1231-1234.

10. G. Cam and M. Kocak, "Progress in Joining of Advanced Materials." International Materials Reviews, 43, No. 1, (1998), pp. 1-44. 
11. R.E. Pease, Weld. J. Res. (Suppl.), (1957), 36, pp. 330-334.

12. Cannon-Muskegon Technical Bulletin, "CM939 Weldable ${ }^{\mathrm{TM}}$ Alloy." August 2002.

13. A. Dhooge and A. Vinckier, "Reheat Cracking - A Review of Recent Studies." Int. J. Pressure Vessels and Piping, 27, (1987), pp. 239-269.

14. M.J. Russell and P.L. Threadgill, "Repair of IN939 Rotor Assembly - Initial Feasibility Studies." TWI Report NO: 12603/1/00, (2000). 